\title{
0 problema dos teoremas-em-ação sobre a força de atrito na disciplina de física geral para graduação
}

Thaís Rafaela Hilger

Ângelo Mozart Medeiros de Oliveira

\section{Resumo}

São apresentados neste artigo, resultados de um estudo sobre erros cometidos por alunos de engenharias da UFRGS, em provas de Física Geral. Algumas pesquisas já antecipavam a dificuldade dos alunos em relação à direção e sentido da força de atrito, principalmente o estático. Com vistas a estas dificuldades, uma questão de prova foi escolhida para ser aqui discutida e serão tratados alguns possíveis teoremas-em-ação utilizados pelos estudantes para tentar resolver esta questão envolvendo o atrito entre superfícies. De acordo com a teoria dos campos conceituais de Vergnaud, o sujeito tenta resolver as situações a ele apresentadas utilizando esquemas compostos por uma série de elementos, entre eles os teoremas-em-ação. Quando um teorema-em-ação não está correto pode levar a erros sistemáticos em problemas, como o caso aqui discutido. Um vasto repertório de esquemas é criado a partir do contato com diferentes situações, tornando o sujeito mais preparado para agir diante de dificuldades.

Palavras-chave: campos conceituais, teoremas-em-ação, Física Geral, atrito.

\footnotetext{
Abstract

The problem of theorems-in-action on the friction force in the discipline of college physics

It is presented in this paper some results of a study on the mistakes made by some students of engineering from UFRGS, in tests of general physics. Some research has already anticipated the difficulty of the students in relation to the direction of the friction force, especially the static one. Aiming at these problems, a quiz question was chosen to be discussed here and to deal with some possible
} 
theorem-in-action used by students to try to resolve issues involving the friction between surfaces. According to the theory of conceptual fields of Vergnaud, the subject attempts to resolve the situations presented by using schemes consisting of a series of factors, including theorems-in-action. When a theorem-in-action is not correct it can lead to systematic errors in problems, such as discussed here. A vast repertoire of schemas is created from the contact with different situations, making the subject more prepared to face new difficulties.

Keywords: Conceptual Fields, Theorems-in-Action, General Physics, Friction.

\section{Introdução}

Com inspiração nos artigos de Caldas e Saltiel (1999a e 1999b), onde são apresentados dois estudos sobre o atrito - o primeiro trata das possibilidades para evitar os erros mais comuns apresentados por alunos, e até mesmo por professores da área, quanto às ideias sobre o atrito, e o segundo sobre como este conceito é apresentado e exemplificado nos livros didáticos mais difundidos ao nível da graduação - e sua relação com o ensino de Física, este trabalho reforça a necessidade de mais atenção à forma como este conteúdo é generalizado nos problemas e exercícios resolvidos tanto em sala de aula, que servem como exemplo dado pelo professor, como nas listas oferecidas aos estudantes.

De acordo com Vergnaud (1982, 1990, 1993, 1996, 1998), o conhecimento é organizado em termos de campos conceituais, que formam um conjunto entrelaçado de conceitos, procedimentos, situações, relações e estruturas, onde nenhum pode ser entendido isoladamente. O domínio de um campo conceitual leva tempo e sua compreensão aumenta de acordo com o contato com situações novas envolvendo esses conhecimentos. Em alguns casos, quando se utiliza um esquema estabelecido para resolver problemas que não estão de acordo com a nova situação, podem ocorrer erros devido a esta generalização.

O campo conceitual de nosso interesse é o da mecânica clássica, especificamente no que tange às relações entre força e movimento. Aqui, boa parte das dificuldades reside no fato de que para os alunos é muito difícil raciocinar em termos de referenciais e de grandezas físicas (CALDAS e SALTIEL, 1999a, p. 359).

Ao invés de definir a força de atrito em termos de movimento relativo entre os objetos, os alunos geralmente associam o aparecimento do atrito a partir de causas dinâmicas, ou seja, se opondo ao movimento em relação a um referencial "verdadeiro", intrínseco. Nesse pensamento surge a ideia de que a força de atrito estático sempre tem um caráter resistente, e dessa maneira, não existe a possibilidade dessa força agir no mesmo sentido do deslocamento de um corpo, dentro de um determinado referencial. Esta ideia é reforçada em alguns livros didáticos (CALDAS 
e SALTIEL, 1999b) e, caso o professor não faça uma ressalva sobre este caso, pode ser criado um obstáculo para a resolução de situações em que o atrito não se opõe ao movimento do grupo de corpos analisados.

Podemos entender também que esta dificuldade se deve à atribuição de oposição do atrito ao movimento puro em si, ou ao movimento do conjunto como um todo. $O$ correto é que o atrito se opõe sim ao movimento, porém é apenas ao movimento relativo de escorregamento entre superfícies, isto é, a oposição será sempre em relação às velocidades relativas de deslocamento das superfícies. Neste último caso é que está correta a suposição inicial de oposição, só que esta oposição será sempre em relação às velocidades relativas de escorregamento.

Assumiremos para este trabalho significados diferentes para os conceitos de movimento e escorregamento. Por movimento, entendemos o deslocamento acelerado ou constante do objeto (ou objetos) dentro do referencial de um observador externo, e não dos próprios objetos, ou em outras palavras, o movimento aparente do objeto ou do conjunto. Associamos escorregamento ao deslizamento que ocorreria entre os objetos considerando o movimento relativo entre eles, na ausência do atrito. Muitas vezes essa diferenciação não ocorre para os alunos, que mesmo para o escorregamento, continuam utilizando o termo "movimento", sendo então natural a confusão entre um movimento considerado intrínseco e movimento relativo (escorregamento).

A fim de ilustrar o sentido da força de atrito e como ela pode atuar no mesmo sentido do movimento, destacamos um caso típico de força de atrito, utilizado por Caldas e Saltiel (1999a, p. 361): dois blocos são colocados um sobre o outro, em repouso sobre uma superfície horizontal e de atrito desprezível, como mostrado na figura 1 , onde $\mathrm{fc}_{12}$ indica a força de atrito que o bloco 1 exerce sobre o bloco 2; $\mathrm{fc}_{21}$ corresponde a força que o bloco 2 exerce no bloco $1 ; \mathrm{F}$ é a força aplicada sobre o bloco $1 ; V_{2 M}$ é a velocidade com que o bloco 2 possui em relação à mesa; $V_{1 M}$ é a velocidade com que o bloco 1 possui em relação à mesa; $V_{12}$ é a velocidade relativa de escorregamento que o bloco 1 teria em relação ao bloco 2 se não houvesse o atrito e, nos mesmos termos, $\mathrm{V}_{21}$ é a velocidade relativa do bloco 2 em relação ao bloco 1.

Com a finalidade de não parecer uma força externa ou uma força resultante, recomenda-se o uso de índices para indicar a origem da força ao invés de simplesmente usar uma letra do tipo "F". Uma vez que as forças sempre ocorrem aos pares, sendo um agente ativo (primeiro indicador) e um agente passivo (segundo indicador), uma força tipo $\mathrm{fc}_{12}$ automaticamente nos dirá que existe uma força do tipo $\mathrm{fc}_{21}$. 


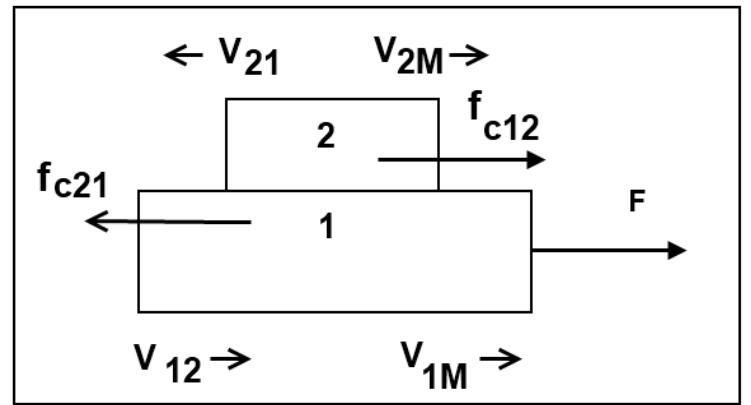

Figura 1 - Um balanço de forças horizontais que atuam nos dois blocos

(Fonte: CALDAS e SALTIEL, 1999a, p. 361).

Dessa maneira, o bloco 2 se movimenta em relação à mesa pela ação da força fc12. Assim, a força de atrito é a única força que age sobre o bloco 2 na horizontal. Esta força está em oposição ao escorregamento, estando também no mesmo sentido que o movimento aparente do conjunto. Quando o sentido da força de atrito é contra-intuitivo, ou seja, quando o significado do termo movimento não é o mesmo de escorregamento, geralmente causa confusão, sendo preciso um maior número de situações para o domínio desse campo conceitual.

\section{Referencial teórico}

Tomando como referência o conteúdo do conhecimento e seu domínio, Vergnaud aponta para a dependência existente entre o desenvolvimento cognitivo e as situações. Diferentemente de seus antecessores, como Piaget (1999) - que acreditava ser necessário o desenvolvimento orgânico, ou seja, a maturação física do indivíduo, para que houvesse um desenvolvimento cognitivo - por exemplo, Vergnaud foca sua atenção nas relações do sujeito em situação, principalmente em sala de aula, no ensino de ciências e matemática, onde os conteúdos a serem aprendidos merecem um enfoque especial. No entanto, não propõe uma teoria de ensino em sala de aula, mas sim uma teoria psicológica, que dá conta do processo de conceitualização, tratando das rupturas e continuidades entre conhecimentos de um conteúdo conceitual (MOREIRA, 2004, p. 8).

Ele parte da premissa de que o conhecimento, composto tanto por competências, expressas por meio de ações adequadas, quanto por concepções, apresentadas sob a forma de seqüências de enunciados, é organizado em campos conceituais, definidos como "um conjunto informal e heterogêneo de problemas, situações, conceitos, relações, estruturas, conteúdos e operações de pensamento, conectados uns aos outros e, provavelmente, entrelaçados durante o processo de aquisição" (VERGNAUD, 1982, p. 40). O domínio de um campo conceitual ocorre lentamente, na medida em que o sujeito é apresentado a novas situações, exigindo maturidade. 
"De fato, se a primeira entrada de um campo conceitual é das situações, podemos também identificar uma segunda, a dos conceitos e teoremas" (VERGNAUD, 1993, p. 9). Assim, a chave do processo é a ação do sujeito frente à situação, quais seus comportamentos e como são desencadeados e organizados.

"Pode-se pensar em situação como um dado complexo de objetos, propriedades e relações num espaço e tempo determinado, envolvendo o sujeito e suas ações" (FRANCHI, 1999, p. 158). Distinguem-se dois tipos de classes de situação, de acordo com as competências que o sujeito dispõe em seu repertório para tratá-las. Se o sujeito não dispõe de todas as competências necessárias para resolver a situação, observa-se que ele precisa refletir sobre como abordar o problema e, então faz tentativas, que podem ou não solucionar a questão, precisando, às vezes, de consecutivas tentativas até obter o sucesso, ou mesmo desistir. O que se observa é "a sucessiva utilização de vários esquemas, que podem entrar em competição e que, para atingir a solução desejada, devem ser acomodados, descombinados e recombinados. Esse processo é necessariamente acompanhado por descobertas" (VERGNAUD, 1993, p. 2). No caso contrário, quando o sujeito dispõe dessas competências, ele se utiliza de comportamentos automatizados, organizados por apenas um esquema e dirigido diretamente para uma mesma classe de situações.

"Chama-se esquema a organização invariante do comportamento para uma classe de situações dada" (VERGNAUD, 1990, p. 136). É importante frisar que a invariância não se refere aos elementos formais da atividade ou às ações do sujeito em si, mas sim a aspectos invariantes na organização dessas ações. Ou, segundo o próprio Vergnaud (1998, p. 172)

"não é o comportamento que é invariante, mas sim a organização do comportamento. Em outras palavras, um esquema é um universal que é eficiente para toda uma gama de situações, e pode gerar diferentes sequências de ações, de coleta de informações e de controle, dependendo das características específicas de cada situação particular."

Um esquema está diretamente ligado às características da(s) situação(ões) em que é adequado e proporciona o vínculo imprescindível entre ação e representação. Então um vasto repertório de esquemas auxilia no desenvolvimento da cognição. O sujeito apresenta comportamentos em função das situações com as quais toma contato. No caso da aprendizagem, a organização de comportamentos é refinada e generalizada de acordo com as situações a que o aprendiz é apresentado.

Um esquema se compõe de uma série de elementos, ou ingredientes, que podem ser classificados em quatro tipos principais: 
- objetivos e antecipações: permitem ao sujeito identificar a finalidade da situação, utilizando-se de etapas intermediárias para alcançá-la, e também eventos ou efeitos que podem ou não ocorrer;

- regras de ação, de apoio e de controle de informações: permitem a geração e continuação da sequência dos comportamentos;

- possibilidades de inferência: permitem decidir quais as regras de ação e antecipações que serão utilizadas imediatamente na situação a partir das informações conhecidas e dos invariantes operatórios disponíveis;

- invariantes operatórios: dirigem o reconhecimento da situação e a tomada de informações, através de elementos explícitos e implícitos que sejam pertinentes.

Os invariantes operatórios são formados por teoremas-em-ação, que são proposições consideradas verdadeiras sobre o real, e por conceitos-em-ação, que são categorias de pensamento (objeto, predicado, etc.) consideradas pertinentes ou relevantes (VERGNAUD, 1996, p. 202).

Por exemplo, no problema "Uma força é aplicada a um bloco de massa $10 \mathrm{~kg}$ deslocando-o por $2 \mathrm{~m}$ em uma superfície horizontal sem atrito, durante $2 \mathrm{~min}$. Sabendo que sua aceleração é constante de $1 \mathrm{~m} / \mathrm{s}$, determine: a) sua velocidade final; b) a força que é aplicada ao bloco.", existem duas ideias ${ }^{1}$ envolvidas: a primeira refere-se à equação horária do movimento e a segunda ao diagrama de forças. Estas duas ideias são tidas como verdadeiras sobre o problema, no entanto a ideia de velocidade é utilizada no item a e a ideia de força é abordada no item $b$. Assim temos dois conceitos-em-ação, velocidade e força, cada um pertinente a um item. Também temos dois teoremas-em-ação, as ideias sobre equação horária do movimento e sobre diagrama de forças, ambos tidos como verdadeiros para o problema.

O exemplo evidencia a existência de uma relação dialética entre conceitos-em-ação e teoremas-em-ação, que não devem ser confundidos. Conceitos são ingredientes de teoremas, mas não são teoremas propriamente ditos, pois não permitem derivações, inferências ou computações. Teoremas são formados por proposições, que permitem derivações, cujas propriedades dão conteúdo aos conceitos. Ambos são essenciais aos esquemas e os esquemas são fundamentais para as situações, pois geram ações, inclusive intelectuais, e só o fazem porque contêm teoremas-em-ação e conceitos-em-ação.

Por outro lado, conceitos-em-ação não são verdadeiramente conceitos, nem teoremas-emação são teoremas. Isso porque os verdadeiros conceitos e teoremas científicos devem ser

1 É utilizado o termo genérico ideias, porque o objetivo aqui é exemplificar a diferença entre conceitos-em-ação e teoremas-em-ação e não explicar a física envolvida na solução. 
explícitos, permitindo que se discuta sua pertinência e veracidade. Normalmente os invariantes operatórios são implícitos, mas podem ser explicitados e, progressivamente, transformados em verdadeiros conceitos e teoremas. Conhecer a diferença entre conceitos cotidianos e científicos é muito útil para analisar o ensino e a aprendizagem escolares. Ao expressá-los, se modifica o status cognitivo dos invariantes operatórios, das regras de ação, dos objetivos, das antecipações e das inferências. Uma proposição explícita pode ser discutida, já uma proposição tida como verdadeira e totalmente implícita, não pode. Assim, o caráter do conhecimento é modificado se ele é comunicável, discutido e compartilhado. (VERGNAUD, 1996, p. 204). Este é o objetivo da aprendizagem.

O domínio de um campo conceitual se faz também através dos próprios conceitos envolvidos nas situações. A partir do contato com as diferentes situações o sujeito passa a entender os conceitos. São elas que conferem o significado aos conceitos, pois se constituem em um conjunto complexo que interliga o sujeito e suas ações ao objeto e suas propriedades. No entanto, um conceito não pode ser reduzido à sua definição, pois é através das situações e dos problemas a resolver que um conceito adquire sentido (VERGNAUD, 1993, p. 1). Chega-se então à definição de conceito como constituído por três conjuntos (S-I-R):

S: conjunto de situações, que conferem ao conceito seu sentido (referente);

I: conjunto de invariantes operatórios associados ao conceito no tratamento da situação (significado);

$R$ : conjunto de representações simbólicas e lingüísticas que permitem representar todos os elementos que envolvem o conceito na situação, como, por exemplo, propriedades, procedimentos, etc. (significante).

O desenvolvimento cognitivo implica o desenvolvimento dos conceitos, sempre como tripleto.

\begin{abstract}
"Uma definição pragmática poderia considerar um conceito como um conjunto de invariantes utilizáveis na ação, mas esta definição implica também um conjunto de situações que constituem o referente e um conjunto de esquemas postos em ação pelos sujeitos nessas situações. Daí, o tripleto $(S, I, R)$ onde, em termos psicológicos, $S$ é a realidade e $(I, R)$ a representação que pode ser considerada como dois aspectos interagentes do pensamento, o significado (I) e o significante (R)". (VERGNAUD, apud. MOREIRA, 2004, p. 11).
\end{abstract}


No entanto, a conduta do sujeito não é determinada unicamente pela conceitualização do real, uma vez que o real só pode ser compreendido através da explicitação de seus aspectos. São os esquemas que dão origem à ação do sujeito, em situação, e a representação que a acompanha, tanto simbólica quanto lingüística. A linguagem apresenta então, como principal função, auxiliar o pensamento, comunicando e representando o real. Por isso a linguagem acompanha atividades não dominadas completamente pelo sujeito, auxiliando no planejamento e na elaboração da seqüência de ações a ser tomada, mesmo que em voz baixa. Para uma situação dominada a ação é automatizada e o sujeito não precisa da vocalização como auxiliar do pensamento. "Recordamos, assim, a função de representação da linguagem, entendida como uma função tríplice: representação dos elementos pertinentes da situação, representação da ação e representação das relações entre a ação e a situação" (VERGNAUD, 1993, p. 19).

Ao tomar contato com uma situação nova, o sujeito tenta utilizar os esquemas previamente estabelecidos. No entanto, a validade de um esquema é sempre limitada a uma classe específica de situações. Por exemplo, um teorema-em-ação pode não ser realmente verdadeiro, atuando como obstáculo e induzindo o aluno ao erro. O sujeito sente a necessidade de estender o esquema dominado a outras situações - por processos de generalização ou descontextualização ou ainda, de aplicar o esquema indevidamente. Nos dois casos emergem raciocínios inadequados, dificultando a aprendizagem e, principalmente, causando erros sistemáticos.

\section{Metodologia}

Em nosso estudo, trazemos alguns comentários com relação à dificuldade de atribuir sentido e direção às forças de atrito por parte dos alunos de turmas de Física básica da UFRGS. Para tal, foram analisadas as provas realizadas por estudantes de Física Geral 1 para engenharias, entre 2008 e 2009 (totalizando três semestres). Uma única questão será abordada aqui, pois é representativa dessa deficiência. A questão foi respondida por 34 alunos, dos quais 28 cometeram o mesmo erro, indicando a aplicação de um teorema-em-ação (aceito como verdadeiro) que neste caso era falso. Nenhum aluno acertou por completo a questão, no entanto cinco respostas foram consideradas satisfatórias, pois apresentavam a interpretação correta, mesmo demonstrando dificuldades algébricas.

Reproduzimos agora, fielmente, a questão que envolve o atrito entre dois blocos e a figura apresentados na prova:

Um bloco de massa $m_{1}=5 \mathrm{~kg}$,empurrado sobre uma superfície horizontal sem atrito, esta em contato com um bloco de massa $m_{2}=1 \mathrm{~kg}$. Os coeficientes de atrito estático entre os dois blocos valem, respectivamente, $\mu \mathrm{e}=0.6$ e $\mu \mathrm{c}=0.4$.

a) Determine a intensidade mínima da força $F$, $F_{\min }$ para que o bloco 2 não caia. 
b) Que força a superfície horizontal exerce sobre o bloco 1 no caso do item a?

c) Se a força aplicada for $3 / 4 \mathrm{~F}_{\min }$, quais são as acelerações resultantes do bloco 1 e do bloco 2 (antes deste tocar no solo)?

A figura 2 ilustra a situação.

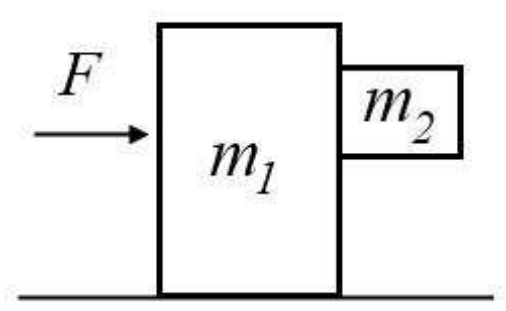

Figura 2 - Dois blocos que se movem sob ação da força F aplicada sobre

o bloco 1.

A seguir será discutido o uso de esquemas sobre o atrito que geralmente são empregados com eficiência em outros problemas mais simples, mas que na resolução da questão proposta foram utilizadas de modo inadequado pelos estudantes.

\section{Resultados}

As provas confirmam o que pesquisas anteriores (CALDAS e SALTIEL, 1999a; 1999b) indicavam quanto às dificuldades sobre direção e sentido das forças de atrito. A figura 3 apresenta o correto balanço de forças para a situação apresentada em prova. As forças não aparecem indicadas como vetores para manter a notação utilizada no enunciado da questão, tal qual foi apresentado na prova.

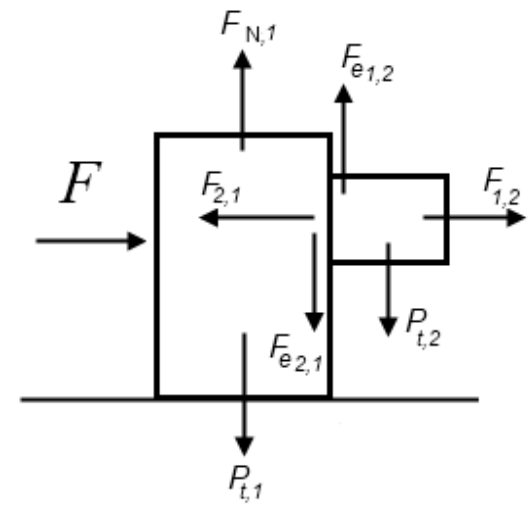


Figura 3 - Balanço de forças esperado.

Onde $\mathrm{F}$ indica a força aplicada ao conjunto; o par $\mathrm{Fe}_{1,2}-\mathrm{Fe}_{2,1}$ representa as forças de atrito que agem no bloco 2 e 1, respectivamente; $P_{t, 1}$ e $P_{t, 2}$ representam a força peso do bloco 1 e 2 , respectivamente; $\mathrm{F}_{\mathrm{N}, 1}$ corresponde à força normal realizada pela superfície horizontal sobre $\mathrm{o}$ bloco $1 ; F_{1,2}$ representa a força que o bloco 1 exerce sobre o bloco 2 , e $F_{2,1}$ o seu par de reação.

O item (a) do problema não envolvia dificuldades, pois a força de atrito apresentava direção e sentido intuitivos. As figuras 4 e 5 mostram resoluções consideradas corretas para este item.



Figura 4 - Primeiro exemplo de resolução correta do item a. 


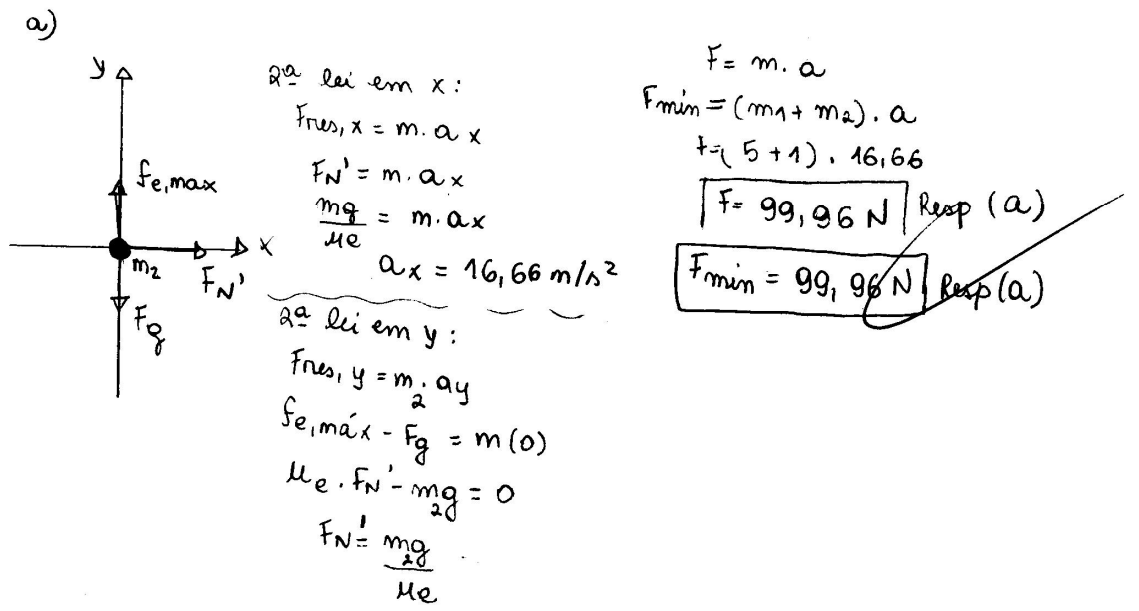

Figura 5 - Segundo exemplo de resolução correta do item a.

Nosso foco está no item (b), pois aqui o aluno deveria considerar a ação da força de atrito no bloco 2 ( $\mathrm{Fe}_{1,2}$ - contrária ao movimento do bloco 2 em relação ao bloco 1), intuitiva e por isso de mais simples identificação, e no bloco 1 , caso contra-intuitivo ( $\mathrm{Fe}_{2,1}$ - na mesma direção do movimento do bloco 2 em relação ao bloco 1). A expressão contra-intuitivo está sendo aplicada aos casos em que os estudantes não consideram a existência dessa força devido a sua direção ser contrária ao esperado, ou seja, não ser no mesmo sentido do movimento. Em geral quando uma situação é considerada conhecida, ocorre a operacionalização do problema. Este é o caso da força de atrito no bloco $2\left(\mathrm{Fe}_{1,2}\right)$, que a maioria dos alunos indicou adequadamente: a direção e o sentido são intuitivos, isto é, apontam na direção oposta ao "movimento" vertical do bloco, correspondendo à maior parte dos exemplos apresentados pelo professor em sala de aula e pelos livros didáticos, além dos exercícios resolvidos pelos alunos. "A repetição é um aspecto importante da formação dos esquemas, pois a familiaridade com as situações é o que mais contribui com a segurança a respeito da informação. Mas a repetição continua sendo um risco a menos que seja compensada por variações" (VERGNAUD, 1996c, p. 203). Ou seja, a repetição ajuda na fixação do conteúdo, porém se as situações apresentadas forem muito similares, a aprendizagem fica restrita. É necessário que os problemas sejam mais variados, envolvendo todos os aspectos que possam contribuir com o entendimento dos conceitos.

No caso do bloco 1 a força de atrito vertical $\left(\mathrm{Fe}_{2,1}\right)$, cuja direção e sentido eram contraintuitivos, apontando na direção do "movimento" (mas na direção oposta ao "escorregamento"), foi simplesmente desconsiderada pela maioria dos estudantes. Este é um indicativo da dificuldade dos alunos em observar que a força de atrito se opõe ao movimento relativo entre as superfícies dos blocos 1 e 2. Assim, ao se considerar apenas o movimento do conjunto, não existe força de 
atrito no bloco 2, pois este permanece em repouso na vertical. Evidentemente esta ideia errônea leva à violação também da Terceira Lei de Newton uma vez que, se existe uma força que age no bloco 2 causada pelo seu contato com o bloco 1, deveria existir uma força agindo sobre o bloco 1 devido ao bloco 2, em sentido oposto e na mesma direção.

Esta mesma dificuldade dos alunos em atribuir à força de atrito o mesmo sentido do movimento no caso em que blocos estão sobrepostos, neste caso a força de atrito aplicada ao bloco 1, foi destacada por Caldas e Saltiel (1999a; 1999b). Apesar de não influenciar no movimento vertical do bloco 1 , a força de atrito estático (força $\mathrm{Fe}_{2,1}$ da figura 3) está presente e é responsável pelo valor correto de $60 \mathrm{~N}$ da força normal $\left(\mathrm{F}_{\mathrm{N}, 1}\right)$. A maioria dos alunos obteve $50 \mathrm{~N}$ para a força normal $\left(\mathrm{F}_{\mathrm{N}, 1}\right)$, pois desconsiderou a força de atrito sobre o bloco $1\left(\mathrm{Fe}_{2,1}\right)$.

Nas figuras 6 e 7 são apresentados dois exemplos de resposta onde não foi considerada a força de atrito sobre o bloco 1, que deveria apontar para baixo.

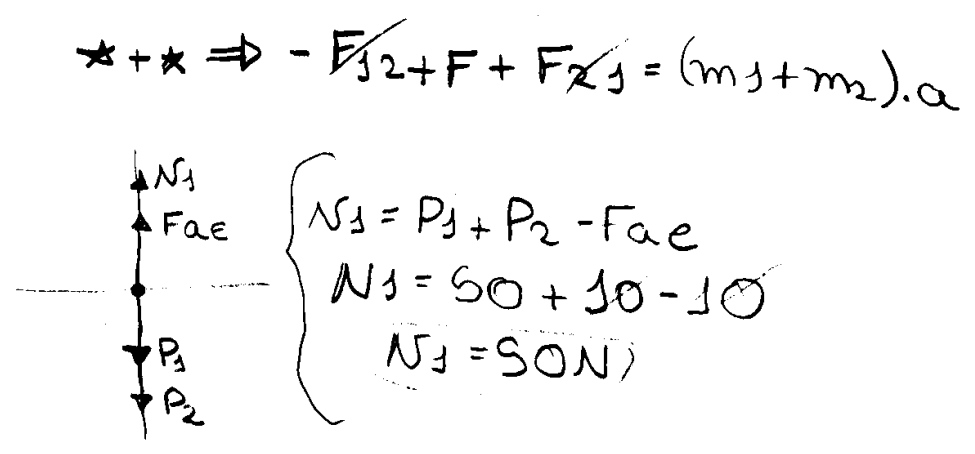

Figura 6-Primeiro exemplo de resposta ao item (b).

$$
\text { l.) } \begin{aligned}
N_{1} & =P_{1} \\
N & =50 \mathrm{~N} \\
N & =50 \mathrm{~N}
\end{aligned}
$$

Figura 7-Segundo exemplo de resposta ao item (b).

Outro fato notável é que estes mesmos alunos geralmente não possuem dificuldade em "montar" o diagrama de forças como é ensinado em sala de aula. Isto pode demonstrar uma 
preocupação operacional elevada nos alunos, que ficam atentos em demasia em montar o problema de forma padrão e não levam em consideração os aspectos teóricos do problema.

Mesmo os alunos que responderam incorretamente o item (b), não reconhecendo a existência da $\mathrm{Fe}_{2,1}$, identificaram que se o bloco 1 exerce uma força de contato sobre o bloco 2, então, em consequência da Terceira Lei de Newton, uma força de contato do bloco 2 sobre o bloco 1, como a sua reação. O mesmo pensamento não ocorre com a força de atrito, ainda que ela seja uma força de contato da mesma natureza do par $F_{2,1}-F_{1,2}$. Em anexo são apresentados diversos diagramas onde os alunos representam corretamente o par $F_{2,1}-F_{1,2}$, mas não o fazem para a força de atrito $\left(\mathrm{Fe}_{2,1}-\mathrm{Fe}_{1,2}\right)$.

O item (c) dependia da resolução do item (a) e, por consequência, não foi acertado pelos alunos que erraram o item (a) de modo independente do acerto/erro do item (b). Os únicos alunos que procederam de modo correto na resolução dos itens anteriores deixaram este último incompleto ou com erros algébricos.



Figura 8-Exemplo de resposta ao item (c).

As dificuldades em relação à força de atrito nos sugerem o uso de teoremas-em-ação, como: "a força de atrito se opõe ao movimento" e "a força de atrito estático existe apenas no bloco que poderia se mover" (assim no bloco 1, que não se movimenta na vertical, não há força de atrito estático). Apesar de serem aceitos como verdadeiros, eles correspondem a situações específicas e, por isso, levam à resolução incorreta deste problema.

Além disso, ignora-se que a força de atrito obedeça à lei da ação e reação. Talvez aqui um possível teorema-em-ação do tipo "a Terceira Lei é válida apenas para forças de contato" 
adicione-se a outro do tipo "a força de atrito não é uma força de contato", porém não temos indícios suficientes para fazer tal afirmação. Outra hipótese é que o problema esteja na identificação das variáveis pertinentes ao problema. Assim a dificuldade estaria nos conceitos-emação do sujeito e não apenas nos teoremas-em-ação.

A melhor abordagem para situações desta espécie deveria iniciar com a identificação das variáveis consideradas relevantes, que desencadearia a ativação do esquema de identificação das forças, determinada pelos conhecimentos-em-ação do sujeito. Com estes elementos se levaria adiante a resolução do problema. Um extenso repertório de esquemas é o que vai determinar quais variáveis são pertinentes e quais proposições são verdadeiras. Mas para isto, o sujeito deve ter contato com diferentes situações, uma vez que um esquema é um universal, dirigido a uma classe de situações e será tanto mais flexível quanto mais variadas forem as situações desenvolvidas (VERGNAUD, 1996c, p. 203).

\section{Conclusão}

Conforme Vergnaud, as situações dão sentido aos conceitos e para resolver estas situações o sujeito deve utilizar-se de seus esquemas. Estes esquemas indicam qual o comportamento e modos de resolução possíveis para o problema em questão. "A educação e a formação devem contribuir na formação de um repertório diversificado de esquemas, evitando que eles se transformem em estereótipos engessados" (VERGNAUD, 1996, p. 203). O uso de exemplos mais explicativos e generalizados por parte do professor - e não apenas os clássicos, do tipo "um bloco sobre uma mesa", onde as forças sobre o bloco são as únicas discutidas, ignorando-se as reações que ocorrem na mesa - desengessa os esquemas do sujeito.

Uma solução para o problema seria a apresentação de diversificadas situações, porém neste caso existe o empecilho natural que é a falta de tempo, uma vez que a disciplina exige muito conteúdo concentrado. Outra opção seria a apresentação em classe de situações semelhantes às abordadas em prova, com ênfase do professor nos obstáculos apresentados pelos alunos. A falta de diferenciação entre conceitos, como o caso do movimento e escorregamento, isto é, entre movimento aparente e relativo, que ocorre nas aulas se reflete nas provas. Os alunos utilizam esses teoremas-em-ação devido à falta de contato com situações diferentes no decorrer do seu estudo em física básica. Também não se deve esquecer que o domínio de campos conceituais leva tempo e depende das diferentes situações desenvolvidas.

Não é coerente que a dificuldade em relação ao atrito, por exemplo, que foi apresentada em outras pesquisas e reiterada neste trabalho, continue sendo deixada de lado. Conceitos complexos demandam situações progressivamente complexas. Quando o professor acredita que para que o aluno aprenda é necessário tão somente a apresentação do conteúdo de forma clara, organizada, rigorosa e formalizada, ocorre aquilo que Vergnaud (apud. MOREIRA, 2004, p. 25) 
denomina "ilusão pedagógica". Trata-se de uma ilusão, pois o estudante precisa de diferentes situações para tornar os conhecimentos significativos, situações estas que devem considerar as dificuldades do aprendiz a fim de que seu desenvolvimento cognitivo atinja o nível de formalismo esperado.

Com este artigo pretendemos fazer um alerta sobre a questão do atrito a fim de evitar que falsos teoremas-em-ação, como os discutidos aqui, continuem sendo disseminados entre os estudantes. Certamente este problema é enfrentado em outros segmentos da Física e de outras ciências exatas, pois a explicitação de conceitos é muito mais complicada nessas áreas.

\section{Referências}

Caldas, H.; Saltiel, E. Sentido das forças de atrito e movimento - I. Revista Brasileira de Ensino de Física, v. 21, n. 3, 1999a.

Caldas, H.; Saltiel, E. Sentido das forças de atrito e movimento - II: uma análise dos livros utilizados no ensino superior. Revista Brasileira de Ensino de Física, v. 21, n. 4, 1999b.

Franchi, A. Considerações sobre a teoria dos campos conceituais. In: Alcântara Machado, S. D. et all. Educação matemática: uma introdução. São Paulo: EDUC. 1999.

Moreira, M. A. A teoria dos campos conceituais de Vergnaud, o ensino de ciências e a pesquisa nesta área. In: Moreira, M. A. A teoria dos campos conceituais de Vergnaud, o ensino de ciências e a investigação nesta área. Porto Alegre: Instituto de Física da UFRGS. 2004.

Piaget, J. Seis estudos de psicologia. Rio de Janeiro: Forense Universitária. 1999.

Vergnaud, G. A classification of cognitive tasks and operations of thought involved in additional and subtraction problems. In: Carpenter, T.; Moser, J.; Romberg, T. Additional and subtraction. A cognitive perspective. Hillsdale, N. J.: Lawrence Erlbaum. 1982.

. A compreensive theory of representation for mathematics education. Journal of Mathematical Behavior, v. 17, n. 2, 1998.

Algunas ideas fundamentales de Piaget en torno a la didáctica. Perspectivas, v. 26, n. 10, 1996.

. La théorie des champs conceptuels. Rechérches en didactique des mathématiques,

v. 10, n. 23, 1990.

. Teoria dos campos conceituais. In: Nasser, L. (Eds.). Anais do 10 Seminário

Internacional de Educação Matemática do Rio de Janeiro. 1993. 
Thaís Rafaela Hilger. Mestre em Ensino de Física pela Universidade Federal do Rio Grande do Sul. Doutoranda do Programa de Pós-Graduação em Ensino de Física da Universidade Federal do Rio Grande do Sul. thais.hilger@ufrgs.br

Ângelo Mozart Medeiros de Oliveira. Mestre em Ensino de Física pela Universidade Federal do Rio Grande do Sul. Doutorando do Programa de Pós-Graduação em Ensino de Física da Universidade Federal do Rio Grande do Sul. angelo.mozart@gmail.com 


\section{Anexo}

São apresentados a seguir alguns diagramas de força obtidos como resposta ao problema proposto.

Tabela A1 - Exemplos de diagramas de forças.

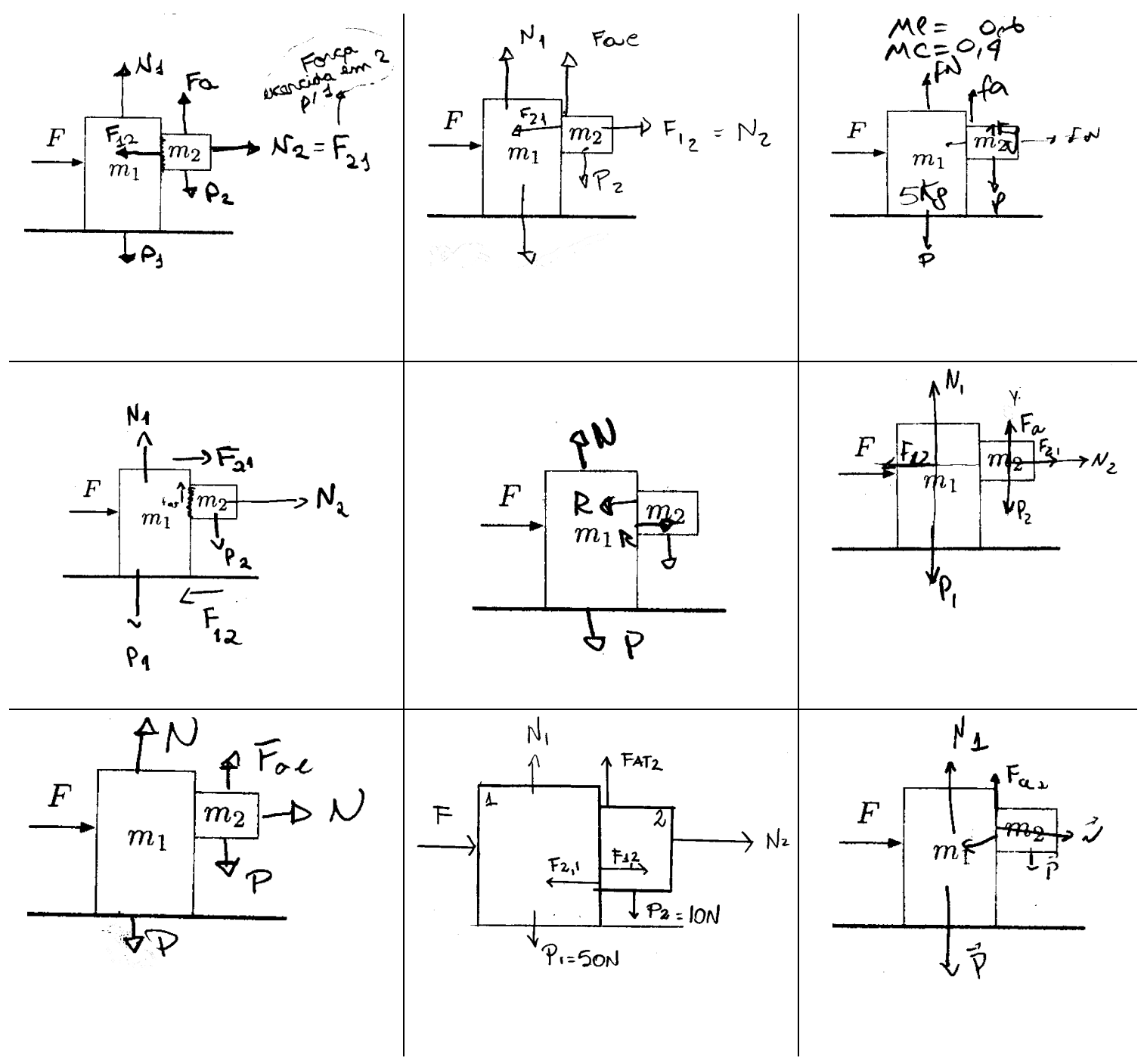

